Cuadernos de Historia Contemporánea

ISSN: 0214-400X

http://dx.doi.org/10.5209/CHCO.56269

\title{
El escritor Nicomedes-Pastor Díaz en el entramado político-financiero de mediados del siglo XIX
}

\author{
Julio Fernández-Sanguino Fernández ${ }^{1}$
}

Recibido: 15 de septiembre de 2016 / Aceptado: 23 de marzo de 2017

Resumen. Nicomedes-Pastor Díaz Corbelle (Viveiro, 1811 - Madrid, 1863) ha pasado a la posteridad como notable escritor y político liberal-conservador de mediados del siglo XIX; sin embargo, su sensible papel en algunos momentos de la política española no ha sido suficientemente indagado, al igual que su destacada participación en el lobby político-financiero que se formó en la Década Moderada no se suele tener en cuenta en sus biografías. Esta última cuestión es el objetivo principal del presente estudio, centrado en una etapa histórica en la que, además de las regresiones en las libertades ciudadanas, se generarían actuaciones promovidas por grupos en el poder tendentes a enriquecimientos indebidos, todo ello en un contexto económico en el que se producirían irregularidades y crisis similares a las habidas recientemente en nuestro país.

Palabras clave: Nicomedes-Pastor Díaz, Década Moderada, lobby político-financiero, enriquecimientos indebidos, irregularidades y crisis económicas.

\section{[en] The Writer Nicomedes-Pastor Díaz in the Political-Financial Framework of the Mid-Nineteenth Century}

\begin{abstract}
Nicomedes-Pastor Diaz Corbelle (Viveiro, 1811 - Madrid, 1863) has passed to posterity as a remarkable writer and liberal-conservative politician of the mid-nineteenth century; however, his prominent role in some moments of the Spanish policy has not been sufficiently investigated and his participation in the political-financial lobby formed in the Moderate Decade is not usually considered by his biographers. This study delves into these last two questions and focuses into a historical scenery in which, in addition to civil liberties regression, some actions tending to undue enrichments were generated, most of them promoted by groups in the power, and in an economic context in which irregularities and crises would have occurred in a similar way as those that happened recently in our country. Keywords: Nicomedes-Pastor Díaz, Spanish Moderate Decade, political-financial lobby, undue enrichment, irregularities and economic crises.
\end{abstract}

Sumario: Introducción. 1. Primeros pasos de Nicomedes-Pastor Díaz en la política española. 2. Oposición al gobierno de Espartero. 3. Ámbito político-financiero en la España de mediados del siglo XIX. 4. Ascenso político de Nicomedes-Pastor Díaz en la Década Moderada. 5. Nicomedes-Pastor Díaz como Rector de la Universidad Central. 6. Participación de Nicomedes-Pastor Díaz en diversas Instituciones y su alejamiento de la vida pública española a finales de la Década Moderada. 7. Últimas actuaciones de Nicomedes-Pastor Díaz en la política española. 8. Los viajes de Nicomedes-Pastor Díaz en el contexto

1 Doctor en CC. EE. y Empresariales, UNED, Madrid (España)

E-mail: juliofs28@gmail.com 
de su época. 9. Consideraciones finales. 10. Archivos y Bibliotecas. 11. Hemeroteca. 12. Referencias bibliográficas.

Cómo citar: Fernández-Sanguino Fernández, J. (2017). "El escritor Nicomedes-Pastor Díaz en el entramado político-financiero de mediados del siglo XIX". Cuadernos de Historia Contemporánea, 39, 129-153.

\section{Introducción}

Nicomedes-Pastor Díaz Corbelle (Viveiro, Lugo, 1811 - Madrid, 1863) fue un destacado escritor y político liberal-conservador del siglo XIX, cuya obra literaria y su pensamiento político han pasado a la posteridad al estar debidamente recogidos en un gran número de publicaciones, que han sido editadas tanto en vida del personaje tratado como en reediciones posteriores.

Ahora bien, mientras que su producción literaria ha sido profusamente analizada, la intensa labor que Nicomedes-Pastor Díaz desarrolló en algunos momentos de su vida, tanto en la política como en los sectores financiero y empresarial, no suele quedar reflejada en sus biografías. Chao Espina indica al respecto que los biógrafos del ilustre personaje vivariense abren un paréntesis de nueve años a partir de 1843, en el cual apenas señalan más hitos que su nombramiento como Secretario General del Banco de Isabel $\mathrm{II}^{2}$.

Asimismo, en sus biografías no se suele profundizar en las relaciones personales que mantuvo en el ámbito político-financiero durante el periodo mencionado, ni se tiene en cuenta generalmente la posible trascendencia o intencionalidad de otras actuaciones suyas. Algunas de ellas suelen ser esbozadas sin analizarse o, incluso, exculpadas sin ningún fundamento, como se aprecia en varios nombramientos que realizó cuando era el responsable de la Instrucción Pública en el país. Se puede citar la designación como catedrático en la Universidad de Oñate del antiguo Rector del Colegio Mayor Fonseca donde Nicomedes-Pastor Díaz había estudiado con anterioridad, señalando al respecto el cronista oficial de su villa natal: "sin tener para nada en cuenta que dicho señor militaba en el partido Carlista"’3.

Castro Calvo, al analizar la obra de Nicomedes-Pastor Díaz, señala que resulta llamativo que en sus biografías se citen los viajes que realizó "sin intento de descubrir la significación profunda" de los mismos o que los numerosos cargos que ostentó se considerasen como "gracia llovida del cielo". Las cualidades de Nicomedes-Pastor Díaz son destacadas por todos aquellos que han estudiado su vida, especialmente su modestia y sencillez, cuestión que llevaría a ese último investigador a razonar que no se le podía ver como un intrigante más en el piélago cortesano de mediados del siglo XIX ${ }^{4}$.

Para tratar de disipar las sombras que surgen en todo este asunto, el presente trabajo se centra en investigar las actividades desarrolladas por Nicomedes-Pastor Díaz en el contexto político-economico que le tocó vivir a mediados del siglo XIX y muy especialmente en el periodo conocido como la Década Moderada.

2 Chao Espina, Enrique: Pastor Díaz dentro del Romanticismo. Alicante: Biblioteca Virtual Miguel de Cervantes, 2012. Edición digital de la obra del Instituto de Estudios Viveireses, Viveiro, 1995, p. 97.

3 Donapetry Iribarnegaray, Juan: Historia de Vivero y su Concejo. Viveiro, I. A. Santiago, 1953, p. 437.

4 Castro y Calvo, José María: Obras completas de Don Nicomedes-Pastor Díaz. Biblioteca de autores españoles, Atlas Ediciones, Madrid, 1969. Estudio Preliminar, p. XLII. 
La figura del escritor y político vivariense se encuentra estudiada en sus biografías, especialmente las que realizaron los cronistas oficiales de su villa natal, junto con otros estudios de analistas de su obra literaria. Su pensamiento político ha quedado reflejado en numerosas publicaciones, fundamentalmente las que se editaron para difundir sus posicionamientos ante cuestiones concretas del momento, así como para recoger sus discursos parlamentarios.

Por otro lado, las fuentes primarias de investigación indicadas sobre el personaje objeto de estudio se complementan con otros textos recogidos en la bibliografía, especialmente de contenidos económicos y financieros, al centrarse el presente trabajo en las actuaciones del escritor y político vivariense en estas facetas que son las menos conocidas, dejándose al margen, en consecuencia, el análisis político de la época tratada que requiere un estudio aparte en otro contexto.

Ahora bien, a la vista de las lagunas existentes en las biografías de NicomedesPastor Díaz y en otros textos relacionados, para fundamentar este estudio se ha precisado de los testimonios de la numerosa prensa editada por aquellos años. Por un lado, el escritor y político vivariense, al igual que otros destacados personajes contemporáneos suyos, tendría un especial protagonismo en los periódicos de la época tratada, publicando numerosos artículos que expresan sus posicionamientos y que permiten precisar algunas de sus posturas ante determinados acontecimientos. Por otro, y dejando al margen cuestiones de opinión, los periódicos de entonces proporcionan una valiosa información que generalmente no se ha tenido en cuenta en los estudios tradicionales del personaje objeto de estudio, principalmente la relacionada con los ámbitos financieros y empresariales de aquella época.

Por este motivo, se han reproducido algunos textos que fueron difundidos en su día por medios de comunicación de amplia circulación, ya que representan una prueba fidedigna de cuestiones que fueron de público conocimiento en la época tratada y que con el paso del tiempo se han ido difuminando y no se han tenido en cuenta las biografías estudiadas.

Por último, cabe significar que, entre las publicaciones de la época analizada, figuran incluidas las gacetas y boletines oficiales que contienen las disposiciones dictadas por aquellos años que acreditan de forma fehaciente la vida pública de Nicomedes-Pastor Díaz, salvado así algunos errores que inexplicablemente se han publicado en sus biografías.

En este sentido, se puede citar a título de ejemplo que Chao Espina señalaba al estudiar la figura del escritor vivariense que todos sus biógrafos, desde Apecechea hasta Valera, afirmaban que en 1848 se le confirió el cargo de Rector de la Universidad Central, aunque Gamallo Fierros decía que su firma en el cargo apareció por primera vez el 30 de septiembre de 1842. En los datos que facilitó al cronista oficial de Viveiro Gabriel Pastor y Galcerán, sobrino de Nicomedes-Pastor Díaz, se precisaba que fue Rector desde el 10 de septiembre de 1847. A la vista de los dispares datos, Chao Espina investigó esta cuestión a través de libros de matrícula y actas de la Universidad, junto con otros documentos de la época. Sin embargo, el nombramiento de Nicomedes-Pastor Díaz como Rector figura oficialmente en la Gaceta de Madrid, antecedente del actual Boletín Oficial del Estado, de la fecha últimamente citada ${ }^{5}$.

5 Chao Espina, Enrique: Pastor Díaz dentro..., pp. 112-114. 


\section{Primeros pasos de Nicomedes-Pastor Díaz en la política española}

Como antecedente, hay que destacar en primer lugar la formación de NicomedesPastor Díaz. Tras las primeras enseñanzas recibidas en los Seminarios de Viveiro y de Mondoñedo, marchó en 1827 a estudiar Leyes en la Universidad de Santiago de Compostela. El cierre de las universidades decretado por Fernando VII hizo que se trasladase, para proseguir sus estudios, a Alcalá de Henares, uno de los pocos centros permitidos al estar bajo control de la Iglesia, donde obtendría el título de abogado en $1833^{6}$.

El escritor Juan Valera señalaría que la lectura favorita de Nicomedes-Pastor Díaz era la Biblia, el Breviario y la Divina Comedia ${ }^{7}$. Asimismo, consideraba que había sido "el más romántico de todos nuestros modernos poetas" y su musa era el "ascetismo austero", cumpliendo en la vida una "misión social y religiosa". Del que fuera su amigo conservaría, "adquiridos por compra después de la muerte del poeta, los cuatro tomos de un Breviario, ricamente impreso en Madrid en 1848, en la lectura de cuyos himnos y oraciones él se complacía de diario como pudiera hacerlo el más fervoroso sacerdote"

Es de sobra conocida la sincera vocación religiosa de Nicomedes-Pastor Díaz, puesta de manifiesto en sus biografías, que resaltan que moriría soltero, la pobreza honrada en la que vivió, la resignación ante las adversidades y su cristiana muerte. Chao Espina destaca igualmente su profunda religiosidad, con la defensa de la Religión en todos sus escritos, razonando que no parecía por ello inverosímil la opinión de Valera acerca de que, tal vez, Pastor Díaz hubiese sido sacerdote de no tener ciertas obligaciones que cumplir?.

En consecuencia, se estima que su formación y sus fuertes convicciones debieron condicionar las actuaciones que desarrolló a lo largo de su vida.

La carrera política de Nicomedes-Pastor Díaz comenzaría durante la Primera Guerra Carlista. Como Jefe Político de Segovia dirigiría el 23 de octubre de 1837 una alocución a los habitantes de la provincia en la que comunicaba su misión tendente, entre otras cosas, a asegurar la paz y tranquilidad, así como poner de manifiesto su fidelidad al trono de Isabel II y a la Regencia de María Cristina de Borbón Dos Sicilias ${ }^{10}$.

En el desempeño de su cargo, pasaría directamente a la acción para informar de los movimientos de tropas de los insurgentes en la provincia y llegaría a salvaguardar de las huestes carlistas los caudales del erario público y de particulares, junto las alhajas de las iglesias, en el Alcázar segoviano ${ }^{11}$. Como presidente de la Diputación Provincial de Segovia que se creó seguidamente, desarrollaría una incesante activi-

6 Fernández-Sanguino Fernández, Julio: “Nicomedes-Pastor Díaz Corbelle en el Colegio de Abogados de Madrid (1845-1853). Heraldo de Vivero, 20/05/2016.

7 Valera, Juan: Obras completas, tomo II, Aguilar 1961, p. 349.

8 Valera, Juan: Crítica Literaria (1901-1905): La poesía lírica y épica en la España del siglo XIX. Madrid, Imprenta Alemana, 1912. "Notas biográficas y críticas: Nicomedes Pastor Díaz”, pp. 18 a 26.

9 Chao Espina, Enrique: Pastor Díaz dentro..., p. 17.

10 Gaceta de Madrid, 1/11/1837, www.boe.es/.

11 Revista La América, 12 de abril de 1863. Recogido por Juan Valera en la Necrología que escribió sobre Nicomedes-Pastor Díaz. 
dad con significativas instrucciones en relación con la desoladora guerra civil que azotaba en aquellos momentos al país ${ }^{12}$.

Se puede apreciar que su implicación hasta el final de esa contienda iría mucho más allá que la de un papel meramente político. En recompensa por sus servicios, el Gobierno premió a Nicomedes-Pastor Díaz con el cargo de magistrado de la Audiencia de Valladolid y poco después sería designado Jefe Político en la provincia de Cáceres ${ }^{13}$.

Desde este cargo, divulgaría en diciembre de 1839 una publicación sobre cuestiones electorales dedicada a los electores y a todos los ciudadanos de la provincia que gobernaba. En este opúsculo de 70 páginas, se aleccionaba sobre lo que se debería de votar en los comicios que se iban a celebrar, mostrándose el autor defensor de la clase política que unos años más tarde ocuparía el poder. De la misma manera, se incluirían una serie de consideraciones que se pueden considerar como retrógradas, incluso ya en aquellos tiempos, al tratar de defender los diezmos ${ }^{14}$.

Otras actuaciones suyas en aquellos momentos serían resaltadas por la prensa. Se puede citar a El Guardia Nacional de 17 de diciembre de 1839, que consideraba como un "ejemplo de verdadero patriotismo" sus gestiones para que se pagasen las contribuciones ante el rechazo general que existía en aquellos momentos por las cargas impositivas que la guerra había generado ${ }^{15}$.

\section{Oposición al gobierno de Espartero}

Nicomedes-Pastor Díaz tendría igualmente una destacada participación en la prensa de entonces, pudiéndose establecer dos vertientes diferenciadoras. Por un lado, la relacionada con su actividad literaria y, por otro, la relativa a su faceta política. Al analizarse esta última, se aprecia en el escrito de 70 páginas que escribió como Jefe político en 1839 que finalizaba refiriéndose al "fanatismo estúpido y el imperio del terror, que afortunadamente solo invocan y proclaman dos monstruos: Cabrera y el Eco del Comercio", metiendo en un mismo saco la dureza de los últimos coletazos de la Primera Guerra Carlista y las informaciones del periódico progresista.

Si los liberales progresistas habían fundado el Eco del Comercio en 1834, al año siguiente se impulsaría El Español como el periódico del liberalismo moderado y reformador, de tendencia monárquico-constitucional. Para ello se creó la primera empresa editorial de la prensa española, constituyéndose como Sociedad Anónima con capital aportado por nobles y terratenientes. Años más tarde, en 1842 se fundaría El Heraldo al servicio del general Narváez y contra el gobierno de Espartero, manteniendo un eminente carácter político y polémico con la prensa progresista, el Eco del comercio y El Clamor Público, principalmente. El Heraldo, que se convertiría en el órgano del Partido Moderado y sería el continuador de El Español y de El Correo Nacional, nacería bajo el subtítulo de "político, religioso, literario e industrial" y, junto a su monarquismo constitucional, se mostraría defensor de la Iglesia y de la

12 Boletín de Segovia, enero 1838, Biblioteca Virtual de Prensa Histórica (en adelante BVPH), http://prensahistorica. mcu.es/.

13 Chao Espina, Enrique: Pastor Díaz dentro..., pp. 61 y 62.

14 Díaz, Nicomedes-Pastor: La cuestión electoral en diciembre de 1839 y enero de 1840. Cáceres, imprenta de don Lucas Burgos, diciembre de 1839.

15 El Guardia Nacional, 1839, Biblioteca Nacional de España (en adelante BNE), http://hemerotecadigital.bne.es/. 
religión católica contra los ataques de los progresistas y demócratas, erigiéndose en aglutinador del conservadurismo más puro, atrayente incluso para algunos sectores del carlismo ${ }^{16}$.

Tras asentarse en Madrid, el escritor vivariense mantendría una línea que se puede estimar hoy día como conservadora en la prensa de entonces, colaborando especialmente con su amigo Pacheco, con el que sería Ministro con posterioridad. Este político y periodista dirigió La Abeja en 1835 y en 1841 sería uno de los fundadores de El Conservador junto con Nicomedes-Pastor Díaz, publicación donde podría expresar sus posicionamientos contra lo que consideraba como las rancias preocupaciones revolucionarias, las teorías modernas que trastornaban la sociedad y las exageraciones democráticas, al mismo tiempo que defendía a ultranza la Monarquía y la Religión. Años más tarde, su labor sería reconocida por otros periódicos, como $E l$ Católico que le calificaba como "uno de estos adalides, muy conocido en el mundo periodístico por aquellos valientes y enérgicos artículos que en otros días aparecían en el Correo Nacional, en el Conservador y posteriormente en el Sol"17.

Tras el fin de la Primera Guerra Carlista, el inicio de la década de los años cuarenta del siglo XIX estaría marcado por la entrada del general Espartero en la política española, provocando duros ataques en la prensa conservadora por sus posiciones progresistas y en los que intervendría activamente Nicomedes-Pastor Díaz con "valientes campañas" como precisa Chao Espina. Este cronista oficial de Viveiro señalaría en la biografía del escritor que, "entre los valientes artículos publicados, sobresale uno contra Espartero", divulgado por El Correo Nacional con motivo de la revista que el 25 de enero de 1841 pasó el general a la Milicia Nacional ${ }^{18}$.

La prensa se convertiría en un factor clave en la lucha contra el Regente en 1842 , junto con otras circunstancias del momento, ya que "no fue solo Pastor Díaz y los redactores de El Conservador los que se encargaron de minar el pedestal de Espartero". Al mismo tiempo que la pluma de Nicomedes-Pastor Díaz y de otros articulistas de El Correo Nacional lanzaban sus ataques contra Espartero, avisaban del peligro republicano ante la situación de la Monarquía en aquellos momentos y el auge que estaba alcanzado el nuevo partido, precisando el último periódico que para poder combatirlo era "conveniente y noble reconocer sus fuerzas y confesar su existencia”. Por otro lado, el escritor vivariense utilizaría la prensa para mostrar su apoyo incondicional a la Corona, publicando en El Sol la necesidad de declarar la mayoría de edad de Isabel II $^{19}$.

Igualmente, desarrollaría una intensa labor contra el gobierno de Espartero en el campo político, con duras interpelaciones que serían recogidas por la prensa del momento, tanto nacional como regional, destacando especialmente los periódicos de Galicia $^{20}$.

16 Registros bibliográficos de la Biblioteca Nacional de España, http://hemerotecadigital.bne.es/.

17 El Católico, 31/10/1844, BNE, http://hemerotecadigital.bne.es/.

18 Chao Espina, Enrique: Pastor Díaz dentro..., p. 385. Chao Espina hace referencia a un artículo con el título de "El Correo Nacional" que se publicó en el periódico de ese mismo nombre el 25/1/1841 sin firma, por lo que era conocedor de la actividad periodística de Nicomedes-Pastor Díaz, poniendo de manifiesto que escribió duros editoriales sin identificarse y que serían asumidos por el periódico. El Correo Nacional, 25/1/1841, BNE, http:// hemerotecadigital.bne.es/.

19 Chao Espina, Enrique: Pastor Díaz dentro..., pp. 81 y 82.

20 Se pueden citar las informaciones de 27/12/1843 de El Centinela de Galicia y del Boletín de Noticias de A Coruña: Galiciana, Biblioteca de Galicia, http://galiciana.bibliotecadegalicia.xunta.es/. 
Su periodismo, comprometido y combativo, iría paralelo a su actuación profesional como abogado. Entre las numerosas informaciones publicadas en esos años, se puede citar las siguientes de enero de 1843 que ponen de manifiesto la situación reinante en aquellos momentos. La Posdata de Madrid recogía que había sido absuelto por un jurado popular un articulista de $\mathrm{El} \mathrm{Sol}$, por diez votos contra dos, ejerciendo la defensa uno de sus redactores, Nicomedes-Pastor Díaz. El juez que llevó el caso sería posteriormente separado de su destino, informando El Heraldo que se debió, entre otras cuestiones, a que no se había prestado a poner en la cárcel a NicomedesPastor Díaz, defensor de un artículo de $\mathrm{El} \mathrm{Sol}$, por algunas palabras fuertemente hostiles al Gobierno que en la defensa pronunción ${ }^{21}$.

En 1843 Espartero se vería obligado a disolver las Cortes, generándose un cambio político en España tras el pronunciamiento militar encabezado por Narváez y Serrano. Nicomedes-Pastor Díaz, que había salido elegido Diputado por Coruña por la oposición en ese año, ocuparía seguidamente escaños dentro del Partido Moderado en diversas legislaturas de la Década Moderada. En la de 1844-1845 por Cáceres, periodo en el que desarrollaría una notable actividad en defensa de la Corona y expondría sus posicionamientos con discursos como el relativo a la "Devolución de los bienes al clero" pronunciado en el Congreso el 17 de marzo de $1845^{22}$.

En 1846 hubo nuevas elecciones a Cortes, presentándose Nicomedes-Pastor Díaz por el distrito de su ciudad natal. Sería derrotado; pero, como señala Donapetry, "su paisano y admirador don Vicente Manuel Cociña le cedió el distrito de Pozo Blanco (Córdoba). Más tarde fue Diputado por Navalmoral de la Mata", Cáceres ${ }^{23}$.

Al margen de cuestiones anecdóticas, con unas prácticas que en la actualidad se pueden considerar como impropias en cualquier democracia, sería en aquellos momentos cuando despegaría definitivamente Nicomedes-Pastor Díaz en la política española.

\section{3. Ámbito político-financiero en la España de mediados del siglo XIX}

En aquellos años, en el ámbito financiero-empresarial cobraría un importante protagonismo el Marqués de Salamanca, recordado por desarrollar el famoso barrio madrileño que tiene su nombre. En el otoño de 1844 protagonizó un pelotazo bursátil en la Bolsa de Madrid, con Narváez ya como presidente del Gobierno, al aprovecharse de las noticias sobre un pronunciamiento militar para provocar una bajada generalizada de la Bolsa de Madrid en la que "quedó arruinado todo el mundo", obteniendo el Marqués de Salamanca cuantiosos beneficios y dando "participación reservada a Narváez y al Duque de Riansares"24.

En octubre de 1846, periódicos como El Imparcial y El Clamor Público ponían de manifiesto que el Duque de Riansares era de hecho el "presidente del gabinete, es decir, jefe de los ministros; es decir, el pensamiento personificado del gobierno". En

21 La Posdata, 7/1/1843. El Heraldo, 21/1/1843. BNE, http://hemerotecadigital.bne.es/.

22 Este tipo de medidas serían apoyadas por los periódicos conservadores del momento, aunque otras publicaciones las criticarían durante, como el Eco del Comercio de 20/6/1844, BNE, http://hemerotecadigital.bne.es/.

23 Donapetry Iribarnegaray, Juan: Historia de Vivero..., p. 437.

24 Estas noticias serían recogidas por la prensa de entonces, aunque las numerosas irregularidades pudieron ser puestas de manifiesto en toda su magnitud con posterioridad, destacándose a La Ilustración española y americana, 30/1/1883, BNE, http://hemerotecadigital.bne.es/. 
cambio, otros periódicos como El Español le defenderían y tratarían de desmentir ciertas informaciones publicadas relativas a que le iban a conceder el título de Príncipe de la Concordia o de las Antillas ${ }^{25}$.

Este último título estaba relacionado con los negocios azucareros que mantenían en Cuba la reina madre María Cristina de Borbón Dos Sicilias y su segundo esposo Agustín Fernando Muñoz y Sánchez, Duque de Riansares. Para ello, se mantendría la trata de esclavos con la connivencia de otros personajes de la época, como O’Donnell cuando ejerció la Capitanía General de la isla entre 1843 y 1848 al cobrar de los negreros una cantidad por cada "pieza" desembarcada ${ }^{26}$.

El mantenimiento de la esclavitud en las regiones tropicales se estimaba como un mal indispensable para la economía española en aquellos momentos, recogiendo la prensa esta cuestión junto con las críticas inglesas, aunque con un evidente trasfondo comercial más que humanitario, que señalaban que estas prácticas no admitían interpretaciones y eran tan claras y elocuentes que Martínez de la Rosa no podía dejar de entenderlas, denunciando las represiones que se llevaban a cabo con frases como "y no se diga que el general O’Donnell continuará impunemente hollando bajo sus pies ensangrentados a los negros de la isla de Cuba"27.

El "tráfico de negros" sería un frecuente titular en los periódicos de esa época, pudiéndose citar las numerosas informaciones publicadas por El Español a lo largo de 1845, con debates que seguirían años más tarde. En este sentido, La Discusión en su ejemplar del 28 de febrero de 1873 preguntaba al Ministro de Ultramar sobre una supuesta compra de mil esclavos para Cuba a pesar de estar prohibido por las leyes, apreciándose que el tema relativo a la abolición de la esclavitud se seguía tratando en las Cortes en aquellos momentos, con posturas en contra del abolicionismo o reticencias como la manifestada por Cánovas del Castillo ${ }^{28}$.

Este tipo de negocios sustentaban una vida de lujo llevada a cabo por la clase social y política más elevada, que se manifestaba públicamente en reuniones y eventos sociales. El hipódromo madrileño adquiriría una relevancia especial y la prensa de entonces informaría de las carreras que se celebraban, con un señalado protagonismo de María Cristina, el Duque de Riansares y el Marqués de Salamanca, junto con toda la jet del momento, comentando algunos periódicos que daba la sensación que el Gobierno de la nación se había establecido en ese lugar ${ }^{29}$.

Entre sus muchas actividades, el Marqués de Salamanca fue uno de los promotores a principios de 1844 del Banco de Isabel II, valiéndose de una más que discutible decisión política, al margen de las reales necesidades financieras del país en aquellos momentos, y que saldría adelante utilizando el nombre de la Reina con la protesta del Banco de San Fernando que tenía el privilegio de emisión en aquellos momentos ${ }^{30}$.

25 El Imparcial, 27/10/1846. El Clamor Público, 28/10/1846. El Español, 28/10/1846. BNE, http:// hemerotecadigital.bne.es/.

26 Un pormenorizado detalle de esta cuestión se puede observar en la obra de Piqueras, José Antonio. La esclavitud en las Españas: Un lazo transatlántico. Catarata, 2012.

27 El Clamor Público, 17-10-1844. BNE, http://hemerotecadigital.bne.es/.

28 El Español, 1845, BNE, http://hemerotecadigital.bne.es/.La Discusión, 28/2/1873, BVPH, http://prensahistorica. mcu.es/.

29 Destacan especialmente las numerosas informaciones aparecidas en los periódicos de 1846 y 1847 , resaltándose las publicadas por El Clamor público, El Español, Diario oficial de avisos de Madrid, La Esperanza o El Heraldo. BNE, http://hemerotecadigital.bne.es/.

30 Banco Español de San Fernando: Representación elevada a S.M. por la Junta de Gobierno del Banco Español de San Fernando: pidiendo que se la ampare en la posesión de la facultad privativa de emitir billetes pagaderos 
Tres años más tarde, en febrero de 1847, el Banco de Isabel II para salvarse de la quiebra se tendría que fusionar con el Banco de San Fernando, creándose una nueva entidad antecesora del actual Banco de España. Ramón de Santillán, que sería nombrado Gobernador de la nueva institución financiera que surgió, precisaría sobre esta cuestión lo siguiente ${ }^{31}$ :

Una actividad casi frenética de especulación, nacida durante la guerra civil (Primera Guerra Carlista), no encontrando auxilios en el Banco de San Fernando, cuyos recursos no alcanzaban a satisfacer las exigencias del Gobierno, produce el Banco de Isabel II, que solo halla alimento en el sostenimiento de especulaciones o más bien en juegos, de que al fin debía ser víctima.

\section{Ascenso político de Nicomedes-Pastor Díaz en la Década Moderada}

A pesar de los escándalos financieros habidos con anterioridad, el Marqués de Salamanca conseguiría su ascensión política en marzo de 1847 al ser nombrado ministro de Hacienda bajo la presidencia de Joaquín Pacheco, posibilitando que los juegos políticos de éste y su posterior y sospechosa dimisión permitiesen que el Marqués de Salamanca pudiera ejercer de hecho la presidencia del Gobierno hasta que tuvo que pedir la dimisión el 4 de octubre de ese año al establecerse una comisión parlamentaria para investigar sus supuestas actividades irregulares ${ }^{32}$.

Algunos medios se atreverían a censurar la gestión del Marqués de Salamanca en aquellos momentos. El Popular, en un duro titular publicado el uno de octubre de aquel año con el título "La revolución en el poder", señalaba que se había utilizado el puesto de Ministro de Hacienda en beneficio propio y que su titular había dictado disposiciones que no cabían en la esfera de la legalidad ${ }^{33}$.

En todo este asunto, resulta, cuanto menos llamativo, que, al mismo tiempo que salía elegido Diputado por Cáceres en 1844, Nicomedes-Pastor Díaz ocupase el puesto de Secretario General en el Banco de Isabel II hasta 1847. Del mismo modo, figuraría en esos años en otras empresas, como se recogería en los anuncios oficiales publicados en la prensa del momento, especialmente en la Junta de Gobierno de la sociedad Camino de Hierro Central de España y en la Junta Gubernativa de la sociedad de productos químicos "La Industriosa" presidida por el Marqués de Salamanca $^{34}$.

Unos días antes de que el Banco de Isabel II llegase a su fin al haberse aprobado su fusión con el Banco de San Fernando, que se haría efectiva el 25 de febrero de 1847, Nicomedes-Pastor Díaz sería nombrado subsecretario del Ministerio de la

a la vista al portador, de la que se le ha despojado por la erección del nuevo Banco de Isabel II con la misma y más amplia facultad, y demostrando la ilegalidad de semejante concesión y los gravísimos inconvenientes económicos que de ella resultan. 1846.

31 Santillán, Ramón de: Memoria histórica sobre los bancos Nacional de San Carlos, Español de San Fernando, Isabel II, Nuevo de San Fernando, y de España. Madrid, T. Fortanet, 1865, Tomo II, p. 237.

32 Gaceta de Madrid, 28 y 30 de marzo, 13 de septiembre y 4 de octubre de 1847, www.boe.es/.

33 El Popular, 1/10/1847, BNE, http://hemerotecadigital.bne.es/.

34 El Español, 30/4/1846, BVPH, http://prensahistorica.mcu.es/. Eco del Comercio, 10/2/1847, BNE, http:// hemerotecadigital.bne.es/. 
Gobernación el 10 de febrero en atención a su trayectoria como Diputado a Cortes y Jefe Político en varias provincias ${ }^{35}$.

En aquellos momentos, el Gobierno reestructuró el Ministerio de la Gobernación del Reino, tras haber creado separadamente un Ministerio de Comercio, Instrucción y Obras Públicas con competencias propias. El 30 de marzo siguiente de ese año 1847 Nicomedes-Pastor Díaz sería designado como titular de la cartera de este último ministerio por Pacheco al hacerse cargo del gobierno de la nación, que incluiría igualmente en su gabinete al Marqués de Salamanca como Ministro de Hacienda ${ }^{36}$.

Las irregularidades en esos años abarcaron innumerables negocios y terminarían implicando a Nicomedes-Pastor Díaz. El Clamor público, periódico del Partido Liberal, informaría el 5 de enero de 1848 que se apreciaba parcialidad e injusticia en el dictamen de la Comisión encargada de examinar los expedientes que se instruyeron contra los últimos consejeros de la Corona en aquellos momentos, señalándose que no solo el Marqués de Salamanca abusó de su posición oficial por favorecer intereses personales en perjuicio del Estado, sino también todos los ministros que, de un modo más o menos directo, tuvieron parte en los expedientes que dieron origen al proceso que se abrió. Asimismo, se precisaba que desde el momento en el que los colegas del señor Salamanca convinieron en favorecer sus intereses, por debilidad, por deferencia o por cualquier otra causa, aceptaron todas las consecuencias de los acuerdos que se adoptaron. De la resolución de este asunto es representativa el siguiente párrafo del periódico en el que se implica a Nicomedes-Pastor Díaz ${ }^{37}$ :

En cuanto al indulto concedido a ciertos defraudadores por la introducción de géneros en Madrid con guías suplantadas de la aduana de Alicante, que es otro de los puntos sobre que versa la acusación, creemos que la principal responsabilidad debe afectar al Ministro de Comercio. En este negocio, el más feo, el más sospechoso de cuantos se imputan a la anterior administración, aparece en extremo solicito y fuera del orden regular el Ministro de Comercio, luchando contra el dictamen de todas las oficinas y contra las leyes y disposiciones vigentes. A primera vista se descubre una afinidad que no queremos calificar, una inteligencia singularísima entre los defraudadores y el Ministro de Comercio, cuyas apasionadas recomendaciones al de Hacienda para que resolviese favorablemente el negocio, iban siempre acompañadas de la peregrina cláusula de que S. M. estaba dispuesta a conceder la Real gracia de indulto. Los oficios del señor Pastor Díaz sobre este asunto pueden casi considerarse como obligatorios para el señor Salamanca, puesto que en todos ellos se invoca el nombre de S. M., suponiendo que había un empeño formal por parte de la Corona en conceder el indulto. ¿Por qué, pues, no pide la comisión acusadora la responsabilidad del señor Pastor Díaz?

Las responsabilidades por los numerosos enriquecimientos indebidos a costa del Estado se difuminarían en aquellos momentos. Años más tarde y una vez finalizada la Década Moderada, La Ilustración comentaría el 24 de julio de 1854 los negocios del Marqués de Salamanca. Se precisaba que a finales de 1852 a Bravo Murillo le reemplazaría el general Roncali del Partido Moderado, señalando el periódico ma-

35 Gaceta de Madrid, 10 de febrero de 1847, www.boe.es/.

36 Gaceta de Madrid, 30 de enero y 13 y 30 de marzo de 1847, www.boe.es/.

37 El Clamor público, 5/1/1848, BNE, http://hemerotecadigital.bne.es/. 
drileño que, al día siguiente de tomar posesión Antonio Benavides como Ministro de la Gobernación del nuevo Gobierno, apareció en la Gaceta oficial un Decreto con su firma sobre los ferrocarriles, tan perjudicial para los intereses públicos como favorable para María Cristina de Borbón-Dos Sicilias y el Marqués de Salamanca. Seguidamente se precisaba lo siguiente ${ }^{38}$ :

Ha existido hasta el célebre 28 de junio (de 1854, fecha en la que comenzó el denominado Bienio Progresista) una sociedad en comandita para la explotación de todos los agios, de todos los negocios que el país había de pagar con su sangre. Capitaneábala Cristina y su gerente Salamanca, monstruo de inmoralidad, era como el vulgo suele decir, su testaferro. Presentarse al negocio de los ferrocarriles en la España comercial y abalanzarse a todos la (sociedad) comandita como manada de lobos hambrientos, fue cosa que a nadie admiró, porque no era de admirar verdaderamente; pero en los primeros instantes no se comprendía la trascendencia de aquella ambición desordenada; a nadie se le alcanzó que abusando de su alta posición política pudieran los explotadores subordinar a sus intereses los intereses sagrados de la nación.

El político y escritor vivariense sería ministro hasta el 31 de agosto de 1847, no formando parte del siguiente gabinete presidido por García Goyena, que duraría tan solo un mes. Como en otras ocasiones, el Marqués de Salamanca se haría de nuevo con el control del Gobierno, ocupando la cartera de Hacienda. Sin embargo, esta vez Nicomedes-Pastor Díaz se mantendría al margen de los enredos políticos del momento, ya que, ante la crisis que se había planteado a primeros de septiembre de 1847, El Heraldo señalaría la siguiente cita que se estima representativa de toda esta cuestión ${ }^{39}$ :

Anteayer decía el Sr. Salamanca que tenía dos combinaciones completas y corrientes, en que no había un solo progresista, sino todos moderados netos, y sin embargo, ayer andaban sus amigos pidiendo poco menos que por Dios a los Sres. Vaamonde y Pastor Díaz que continuasen, a lo cual se negaron estos ministros con una entereza que les honra.

\section{Nicomedes-Pastor Díaz como Rector de la Universidad Central}

Nicomedes-Pastor Díaz no formaría parte del último gobierno en el que estuvo el Marqués de Salamanca. Sin embargo, a pesar de las actuaciones irregulares y polémicas publicadas por los periódicos de entonces expuestas con anterioridad, tras su cese como ministro de Comercio, Instrucción y Obras Públicas fue nombrado Rector de la Universidad Central de Madrid el 9 de septiembre de 1847, lo que puede poner de manifiesto su compromiso con la clase política de entonces y la confianza puesta en él por el Partido Moderado en aquellos momentos ${ }^{40}$.

8 La Ilustración, 24/7/1854, BNE, http://hemerotecadigital.bne.es/.

39 El Heraldo, 1/9/1847, BNE, http://hemerotecadigital.bne.es/.

40 Gaceta de Madrid, 10 de septiembre de 1847, www.boe.es/. 
Narváez se haría cargo del siguiente Gobierno, desde el 4 de octubre de 1847 hasta el 19 de octubre de 1849. El nombramiento como Rector de Nicomedes-Pastor Díaz coincide con una etapa de restricciones en la Universidad, que harían que se pareciese más a un colegio que a un centro de conocimiento superior, donde los estudiantes no podían ni asociarse ni tan siquiera reunirse. Tras la reglamentación ministerial que impulsó Nicomedes-Pastor Díaz, a partir de 1847 "los profesores vienen a convertirse en policías de la conducta estudiantil" 4 .

Asimismo, los investigadores Hernández Sandoica y Peset Reig ponen de manifiesto que, en aquellos momentos, se reglamentarían las penas por lo que se consideraba como excesos estudiantiles y hasta las sanciones por ausencias. El control se impondría hasta tal punto que una simple alteración en el aula obligaba al catedrático a interrumpir las clases. Los profesores sufrirían especialmente las restricciones impuestas, ya que los Jefes de Departamento deberían averiguar los posicionamientos de los docentes. Si se estimaba que sus doctrinas no eran las acertadas, se debería amonestar al profesor para que corrigiese sus yerros si eran meramente científicas; pero si dichas doctrinas fuesen subversivas o consideradas contrarias a los dogmas de la Religión, se daría cuenta al Gobierno para la resolución conveniente ${ }^{42}$.

Estas medidas venían precedidas por otras igualmente restrictivas que fueron impulsadas por los gobiernos de esos años. Se puede citar el desarme y desaparición de la Milicia Nacional, ya que, al ser una fuerza popular de ámbito local, quedaba fuera del alcance de los gobernantes de Madrid y, además, podía estar influenciada por las personalidades más destacadas del lugar, consideradas de tendencia liberal en la mayoría de los casos. La prensa de febrero de 1844 informaría que habían entregado sus armas las Milicias de las principales ciudades, Viveiro entre ellas ${ }^{43}$.

Al mismo tiempo, se fundaría el 13 de mayo de 1844 la Guardia Civil como sucesora de la Santa Hermandad, que se constituiría como un cuerpo militar sumiso al Gobierno central y bajo control del Ministro de la Guerra. De este modo, "la Guardia Civil no solo era crucial para defender al gobierno de turno de quienes quisieran derrocarlo, sino también necesaria para hacer cumplir las leyes fuera de Madrid"44.

La Milicia de la villa natal de Nicomedes-Pastor Díaz mantenía un gran prestigio y había recibido importantes felicitaciones por sus actuaciones, especialmente en defensa de la costa lucense y en la lucha contra el contrabando ${ }^{45}$. Al año siguiente de su desaparición, entraría en vigor una nueva Constitución, que reformuló la de 1837 en un sentido más conservador ${ }^{46}$. Asimismo, en 1845 saldría la Ley de Ayuntamientos, que reforzaba el centralismo y reservaba al Gobierno el nombramiento de alcaldes, y al año siguiente se probaría una nueva Ley Electoral, que restringiría el sufragio ${ }^{47}$.

Nicomedes-Pastor Díaz perdería las elecciones de 1846 a Diputado por Viveiro, a pesar de ser la persona más representativa del lugar. Se estima que las medidas anteriormente indicadas podrían haber influido en su derrota electoral, aunque esta

41 Elena Hernández Sandoica y José Luis Peset Reig: Universidad, poder académico y cambio social: (Alcalá de Henares 1508-Madrid 1874). Ministerio de Educación, Madrid, 1990, p. 198.

42 Elena Hernández Sandoica y José Luis Peset Reig. Universidad, ..., p. 197.

43 Se puede destacar la información de El Heraldo del 16/2/1844. BNE, http://hemerotecadigital.bne.es/.

44 Blaney, Gerald: "La historiografía sobre la Guardia Civil. Crítica y propuestas de investigación". Política y Sociedad, 2005, 42,3, pp. 31 a 44.

45 Fernández-Sanguino Fernández, Julio: Viveiro en la prensa histórica (1741-1850). Madrid, Visión Libros, 2012, pp. 27 y 93.

46 Vera Santos, José Manuel:.La reforma constitucional en España. La Ley, Las Rozas, Madrid, 2007, p. 91.

47 Gaceta de Madrid, 15/1/1845 y 21/3/1846, www.boe.es/. 
cuestión, como otras muchas, no se suele analizar con objetividad. Para Chao Espina, su fracaso se debió al "repetidísimo axioma: nemo propheta in patria sua", afirmando seguidamente que lo mismo sucedería "al pródigo banquero D. José Salamanca, derrotado por el distrito de Málaga, en el cual sus compatriotas le negaron inmerecidamente sus votos" $" 48$.

\section{Participación de Nicomedes-Pastor Díaz en diversas Instituciones y su alejamiento de la vida pública española a finales de la Década Moderada}

Tras su participación en el Gobierno, sería a partir de 1847 cuando Nicomedes-Pastor Díaz desarrollase igualmente su mayor actividad pública en importantes instituciones del país. Dos meses después de ser designado Rector de la Universidad Central tomaría posesión como académico de la Real Academia Española de la Lengua con un discurso que se difundiría en la Gaceta oficial española ${ }^{49}$.

Asimismo, por aquellas fechas Nicomedes-Pastor Díaz figuraría matriculado en el Colegio de Abogados de la capital del Reino y mantendría una destacada presencia en el Ateneo de Madrid. Algunos de los posicionamientos del político vivariense en aquellos momentos serían difundidos por la prensa. Se puede destacar a La Patria, periódico fundado por Pacheco, que recogería "Los problemas del socialismo" que Nicomedes-Pastor Díaz había expuesto en el Ateneo de Madrid en el curso 18481849. En sus conferencias, consideraba al socialismo como subversivo para la paz y equilibrio del Estado y se opondría vehementemente a las nuevas doctrinas sociales que iban saliendo, confiando que fuese la Religión la única que pudiese resolver los conflictos sociales del momento ${ }^{50}$.

El escritor vivariense había colaborado en la refundación del Ateneo en 1835, estimándose que estas últimas consideraciones contra el socialismo no eran fruto de posiciones razonadas dentro de los debates promovidos por esa Institución, sino tendentes a desacreditar a la nueva corriente social, ya que tuvieron lugar en unos momentos delicados después de la Revolución de 1848 que había sacudido a toda Europa y que provocó insurrecciones en España al tener importantes repercusiones en los movimientos obreros y en la burguesía más liberal. Sus conferencias serían alabadas por la prensa conservadora, apareciendo algunas críticas en periódicos progresistas como El Clamor Público, que incluyó un artículo con frases como ${ }^{51}$ :

Su teoría, cien veces más dura, cien veces más desapiadada que la de los escritores que le han precedido, descansa en el principio de que los gobiernos no deben ocuparse del alivio de los males sociales... Aun va más allá. Se funda en el Evangelio, en el palladium de nuestras creencias, en el código divino, que hace diez y ocho siglos pregona por el mundo "amaos los unos a los otros", para aconsejar á los gobiernos: estaos quietos, vuestros esfuerzos luchan en vano con el destino.

48 Chao Espina, Enrique: Pastor Díaz dentro del Romanticismo..., p. 106.

49 Gaceta de Madrid, 9, 17 y 21 de noviembre de 1847, www.boe.es/.

50 La Patria, 1, 7, 21, 22, 24 y 27 de abril y 3, 18 y 19 de mayo de 1849. BNE, http://hemerotecadigital.bne.es/.

51 El Clamor público, 16/12/1848. BNE, http://hemerotecadigital.bne.es/. 
Por otro lado, cabe destacar que en aquellos años existieron diferentes corrientes de opinión dentro del Partido Moderado. En este sentido, el periódico madrileño La Épo$c a$ nos ilustra que entre los "conservadores" de entonces había tantos matices como personas: puritanos antiguos, como Pastor Díaz; puritanos convertidos, como Benavides; anti-puritanos, como Ríos Rosas; entre otros muchos grupos o camarillas ${ }^{52}$.

En consecuencia, se estima que esta diversidad de corrientes de opinión, junto con la inestabilidad política que se produjo en los últimos años de la Década Moderada, desencadenó que se desmarcasen de los gobiernos finales de esa etapa, o fueran relegados, muchos de los políticos considerados afines con anterioridad. Podría ser el caso de Nicomedes-Pastor Díaz, cuya destacada presencia en la vida pública española se fue restringiendo a medida que se alejaba de los posicionamientos de los últimos gobiernos de la Década Moderada.

Ante la falta de concreciones al respecto en sus biografías, es representativa la reseña de La Patria del 3 de abril de 1850 en la que se comentaba que hacía algún tiempo que corrían ciertas noticias acerca de la separación del Sr. Pastor Díaz del cargo que ejercía de Rector de la Universidad de Madrid. Aunque se esperaba esta medida, ante lo que consideraban como la inconsecuencia de algunas personas y la falta de método del gabinete gubernamental en aquellos momentos, el periódico precisaría que "no creíamos que sin motivo de ninguna especie, y solo por complacencias personales; que debieran siempre estar muy lejos de los que gobiernan los estados, se separase a un digno funcionario el cargo que desempeñaba" 53 .

Se citaba a Moyano como sucesor de Nicomedes-Pastor Díaz en el puesto de Rector de la Universidad de Madrid, confirmándose posteriormente su designación para este cargo. Asimismo, al contar con el apoyo de los nuevos gobiernos, Moyano sería nombrado después Ministro de Fomento, puesto en el que tan solo duraría algo menos de dos meses $^{54}$.

Del mismo modo, se puede mencionar la presencia de Nicomedes-Pastor Díaz en el Colegio de Abogados de Madrid, faceta que es generalmente desconocida por los historiadores. El escritor vivariense solicitó en 1845 la colegiación para poder ejercer el noble oficio de la abogacía coincidiendo con su mayor actividad empresarial. A finales de 1853 remitiría un oficio comunicando que no ejercía, según era público y notorio, la profesión de abogado desde hacía algún tiempo, por lo que solicitaba que se le excluyera "del número de los del Colegio de esta Corte que satisfacen en aquel concepto cuota por la contribución del subsidio, y se me comprenda entre los demás individuos del Colegio que no ejercen la abogacía"55.

Nicomedes-Pastor Díaz siguió con su labor parlamentaria hasta 1852. A principios del año siguiente, los periódicos informarían de las nuevas elecciones a Cortes, comicios en los que se presentaría como candidato de la oposición en contra del candidato ministerial por Navalmoral de la Mata en Cáceres. Posteriormente, la prensa señalaría que se había retirado, habiendo salido elegido el candidato antireformista ${ }^{56}$.

La Época 27/7/1850, BNE, http://hemerotecadigital.bne.es/.

La Patria, 3/4/1850, BNE, http://hemerotecadigital.bne.es/.

Gaceta de Madrid, 06/04/1851 y 22/06 y 03/08 de 1853, www.boe.es/.

55 Ilustre Colegio de Abogados de Madrid, Secretaría, Biblioteca y Servicio de Documentación Jurídica, Expediente 4007 de 1845.

56 La España, 26/1/1853. La Época, 7/2/1853. BNE, http://hemerotecadigital.bne.es/. 
Su inhibición en la actividad pública en aquellos momentos generalmente se relaciona con el ámbito político sin referencias a otras facetas en las que tuvo un papel relevante, especialmente en marco cultural, al igual que en su anterior faceta financiera. A pesar de las evidencias expuestas, su inactividad se suele edulcorar, incluso en páginas webs de amplia difusión, con frases como que "su salud y su negativa a aceptar ciertos cambalaches políticos lo apartan progresivamente de la política" 57 .

En aquellos momentos se aprecia el retraimiento de Nicomedes-Pastor Díaz en su faceta periodística, teniendo que sufrir igualmente los inconvenientes derivados de las restricciones informativas que se impusieron al final de la Década Moderada. Tras instaurarse el Bienio Progresista, La Ilustración haría un resumen de la situación vivida en unos momentos en los que "la prensa periódica mientras tanto iba como esclava atada al carro de la tiranía". La publicación incluiría igualmente el manifiesto que los principales escritores españoles de periódicos públicos, amantes de la independencia y del decoro de la libertad de imprenta, habían suscrito el 12 de enero de 1854 apoyando a los periódicos reprimidos y protestando contra las ilegalidades del Gobierno, que, además de aplicar con dureza la censura decretada, llegaron "hasta el extremo inconcebible de indicar expresamente a las redacciones de los periódicos que se abstuviesen, so pena de recogida, de tratar ni esencial ni circunstancialmente" determinados asuntos, entre los que figuraban los relacionados con los ferrocarriles dado el escándalo que habían suscitado. El escritor vivariense suscribiría el manifiesto mencionado junto con Pacheco en el último instante, observándose que había dejado aparcada su actividad periodística en aquellos momentos donde algunos medios serían utilizados como instrumentos partidistas con el manejo de la información, tanto con finalidades políticas como económicas para difundir noticias interesadas ${ }^{58}$.

El ejemplar de La Ilustración indicado da igualmente la siguiente visión de los últimos gobiernos de la Década Moderada, momentos en los que Nicomedes-Pastor Díaz se mantuvo al margen de la política. El gabinete de Bravo Murillo en 1851 recibiría numerosas denuncias porque se intentó cambiar el sistema de gobierno para poder, "de acuerdo con Cristina, hacer el magnífico negocio del arreglo de la Deuda", quedando tan minado el edificio político español, que era inevitable su ruina a juicio del articulista. El posterior ministerio de Roncalli, al que se le calificaba de tendencias absolutistas, no saldría igualmente bien parado al "contraer un empréstito onerosísimo y escandaloso" para los intereses de los españoles.

De la misma manera, no se aprecian en los últimos años de la Década Moderada actuaciones relacionadas con el ámbito empresarial posteriores a las indicadas en las que interviniese Nicomedes-Pastor Díaz, de lo que se puede deducir que se desmarcó de un tipo de actividades poco edificantes que siguieron manteniendo algunas personas con las que había colaborado con anterioridad, especialmente el Marqués de Salamanca.

Este empresario seguiría tanto en la política como en el ámbito económico, pero a partir de 1860 su carrera empezaría a declinar y su patrimonio disminuía rápidamente por los sucesivos negocios que no terminaron de prosperar en una situación

57 https://es.wikipedia.org/wiki/Nicomedes_Pastor_D\%C3\%ADaz (diciembre 2016).

58 La Ilustración, 24/7/1854, BNE, http://hemerotecadigital.bne.es/. 
económica cada vez más complicada en el país, que terminaría en la primera crisis financiera de la historia del capitalismo español a principios de $1866^{59}$.

La crisis se generalizaría y afectaría igualmente a otros sectores, especialmente al inmobiliario. La especulación del suelo en Madrid sufrida años antes produciría lo que se conoce actualmente como una burbuja inmobiliaria y acarrearía el posterior desplome del mercado con la quiebra de importantes compañías inmobiliarias ${ }^{60}$.

\section{7. Últimas actuaciones de Nicomedes-Pastor Díaz en la política española}

La caótica situación que se vivía en España al final de la Década Moderada, con una clara violación de los usos parlamentarios por parte de la Corona, provocó el acercamiento de distintas fuerzas políticas, generándose un pronunciamiento que daría lugar al periodo conocido como Bienio Progresista, con un especial protagonismo de los demócratas y progresistas, junto con otras fuerzas integradas por algunos de los moderados y puritanos.

Nicomedes-Pastor Díaz, que se habían mantenido al margen de la política hasta aquellos momentos, sería nombrado el 9 de agosto de 1854 Enviado Extraordinario y Ministro Plenipotenciario cerca de S. M. el Rey de Cerdeña. Se puede apreciar que la vuelta a la política de Nicomedes-Pastor Díaz vino de la mano de su buen amigo Joaquín Francisco Pacheco con el que había estado en el Gobierno con anterioridad y que, como Ministro de Estado en el primer gobierno de Espartero al inicio del Bienio Progresista, firmaría su nombramiento ${ }^{61}$.

En su nuevo destino escribiría una importante obra en defensa e independencia del Pontificado, proclamando la primacía y la universalidad de Roma por encima de la Italia terrenal. Asimismo, esta obra, de marcado catolicismo, disiparía dudas y tensiones que ya habían empezado a limarse entre España y la Santa Sede tras la firma en 1851 del Concordato tan deseado por el Partido Moderado ${ }^{62}$.

Posteriormente, el general O’Donnell, que presidiría el primer Gobierno que se formó después del Bienio Progresista, contaría en julio de 1856 con NicomedesPastor Díaz como Ministro de Estado, cargo que desempeñó hasta octubre de ese año al hacerse cargo del Gobierno Narváez. Años más tarde, cuando O’Donnell volvió a ocupar la Presidencia del Consejo de Ministros, contaría en diferentes ocasiones nuevamente con Nicomedes-Pastor Díaz, primero le designó en julio de 1859 Enviado extraordinario y Ministro Plenipotenciario en Portugal y al inicio de 1863 le nombraría titular de Gracia y Justicia ${ }^{63}$.

Nicomedes-Pastor Díaz, al integrase nuevamente en la política, volvería a tener un relevante papel en la vida pública española, destacando, entre otros cargos y distinciones, su ingreso en 1857 en la Academia de Ciencias Morales y Políticas ${ }^{64}$.

59 Fuentes, Juan Francisco: El fin del Antiguo Régimen (1808-1868). Política y sociedad. Madrid: Síntesis, 2007, pp. 229 y 230.

60 Se puede destacar el conocido caso de "La Peninsular", que terminaría entrando en concurso de acreedores con el embargo de sus fincas en Madrid. El Imparcial, 14/5/1870, BNE, http://hemerotecadigital.bne.es/.

61 Gaceta de Madrid, 09/08/1854, www.boe.es/.

62 Diaz, Nicomedes-Pastor:. Italia y Roma. Roma sin el Papa. Madrid, Imp. de Manuel Tello, 1866.

63 Gaceta de Madrid, 14/07 y 13/10 de 1856, 15/07/1859 y 20/01/1863, www.boe.es/.

64 La Discusión, 2-12-1857, BNE, http://hemerotecadigital.bne.es/. 
En su última etapa como político, desarrollaría una infatigable labor de acuerdo con sus principios hasta el final de su vida. Es significativo que, a pesar de estar muy enfermo y a menos de dos meses de su fallecimiento, como ministro de Gracia y Justicia pronunciase en el Senado el 27 de enero de 1863 un "Discurso contestando al señor Rodríguez Carnaleño sobre su propósito para que dejase el clero de cobrar los derechos de estola" ${ }^{65}$.

Al igual que con su dedicación a la política, Nicomedes-Pastor Díaz a su vuelta de Turín retomaría su actividad periodística hasta el final de sus días. En 1863 sería uno de los principales impulsores de La Concordia junto con Pacheco. El periódico reproduciría fragmentos de la obra que había escrito años antes en defensa del Pontificado. La revista finalizaría al año siguiente tras fallecer Nicomedes-Pastor Díaz y se creó para plasmar el cuerpo ideológico en el que se sustentaba el hegemónico conservadurismo español representado en el Partido Moderado como mantenedor del régimen isabelino ${ }^{66}$.

Todos los biógrafos de Nicomedes-Pastor Díaz han resaltado que moría pobre, llevando una vida austera al margen de los dispendios que realizó la clase política con la que estuvo vinculado, especialmente en la Década Moderada. Sin embargo, gozaría de importantes emolumentos en los significativos cargos que desempeñó hasta su fallecimiento, incluso en los pocos momentos en los que estuvo al margen de la política. En este sentido, el periódico madrileño La Nación el 25 de abril de 1854 citaba a los 103 ex-ministros que habían desempeñado funciones hasta esa fecha, entre los que figuraba Nicomedes-Pastor Díaz que había ejercido unos meses de 1847, desde el 28 de marzo al 31 de agosto, como Ministro de Comercio, Instrucción y Obras Públicas. Excluyendo los que estaban empleados, el periódico señalaba que cobraban la cesantía de ministro 53 individuos que percibían una cantidad mínima anual de treinta mil reales ${ }^{67}$.

Al morir soltero, en la sesión de las Cortes celebrada el día 11 de abril de 1863 se aprobó una proposición formulada por los señores Valera, Vizconde del Pontón, Rivero, Ríos Rosas, Salamanca, Aguirre y González Bravo para conceder a la madre y hermanas de Nicomedes-Pastor Díaz una pensión, de carácter extraordinario y muy difícil de conseguir en aquellos años, de quince mil reales anuales ${ }^{68}$.

\section{Los viajes de Nicomedes-Pastor Díaz en el contexto de su época}

Se estima que los últimos nombramientos indicados con anterioridad no fueron por casualidad como algunos biógrafos sugieren. Nicomedes-Pastor Díaz había conocido al general O'Donnell durante la revolución de 1840 al haber sido comisionado para ir a Valencia con la finalidad de ofrecer a la Reina Gobernadora la formación de un gobierno de unidad nacional. En aquellos momentos, también se mostraría fiel servidor de la causa Diego de León, que portaba una lista con dieciocho generales

65 Castro y Calvo, José María: Obras completas de..., p. 409.

66 La Concordia, 1863-1864. Registro bibliográfico de la Biblioteca Nacional de España, http://hemerotecadigital. bne.es/.

67 La Nación, 25/4/1854, BNE, http://hemerotecadigital.bne.es/.

68 El Contemporáneo, 12/4/1863, BNE, http://hemerotecadigital.bne.es/. 
más. Al final, María Cristina renunciaría a la Regencia que sería ejercida por Espartero $^{69}$.

En todo este asunto, el político vivariense pudo tener un papel más importante del que se ha querido mantener, especialmente tras el fracaso de su cometido. Es significativo que en la biografía que se realizó en 1847 cuando ya estaba en el Gobierno figurase sin más: "En Madrid se dijo que Pastor Díaz había tenido gran parte en los sucesos de Valencia. No tuvo ninguna, nada de cuanto aconsejó, se llevó a cabo"70.

A su regreso a Madrid, Nicomedes-Pastor Díaz sería encarcelado durante dos meses por su participación en el complot que terminaría en un fallido alzamiento militar. La ejecución de su entrañable amigo, el general León, le afectaría muy especialmente, plasmando en una sentida obra su biografía ${ }^{71}$.

En relación con los viajes que emprendió Nicomedes-Pastor Díaz, se aprecia discreción y un cierto confusionismo, tanto en los momentos en los que se realizaron, como posteriormente en sus biografías. El Correo Nacional señalaría el 24 de septiembre de 1840 que sabían de algunas informaciones y rumores que habían circulado acerca de que el político vivariense había sido nombrado Subsecretario de Estado en Valencia con motivo del viaje que realizó, precisando el periódico que no informó en su momento al saber que no eran exactas las noticias que circulaban, aunque silenciaría los verdaderos motivos expuestos con anterioridad ${ }^{72}$.

Castro Calvo precisa que nada decían los biógrafos de Nicomedes-Pastor Díaz del origen y causa de sus viajes a Bayona y Londres en 1845 y a Sevilla en $1848^{73}$. Los primeros tendrían claras finalidades políticas que ponen de manifiesto los manejos por salvar la caduca dinastía de los Borbones en aquellos momentos y la injerencia extranjera, especialmente de Inglaterra y Francia, en el destino de la Corona española, como se puede apreciar en la siguiente reseña publicada por varios periódicos españoles ${ }^{74}$ :

Algunas cartas de Francfort empiezan a hacer comentarios sobre la reunión de diplomáticos a orillas del Rhin. Según dicen, la diplomacia inglesa, austríaca y prusiana, ha tenido muchas conferencias sobre asuntos políticos. Las de lord Aberdeen y el príncipe de Metternich han sido graves y prolongadas. Añaden que se han desechado las candidaturas de un príncipe do Coburgo y del conde de Trápani, para el matrimonio de la reina de España, y que Rusia, Inglaterra, Austria y Prusia están igualmente de acuerdo en la exclusión de un príncipe de Orleans.

Este último viaje acredita la implicación de Nicomedes-Pastor Díaz en las cuestiones dinásticas españolas en un año complicado para él, con una intensa labor parlamentaria y un pesado trabajo en el Banco de Isabel II. Además, tuvo que realizar,

69 Chao Espina, Enrique: Pastor Díaz dentro del Romanticismo..., pp. 72 y 73.

70 Ovillo y Otero, Manuel, dir: Historia de las Cortes de España y Biografías de todos los Diputados y Senadores más notables contemporáneos. Tomo II, Imp. Baltasar González, Madrid, 1847, p. 384.

71 Díaz, Nicomedes-Pastor: Biografía de Don Diego de León, primer conde de Belascoain. Madrid, Imp. de Manuel Tello, 1868.

72 El Correo Nacional, 24/9/1840, BNE, http://hemerotecadigital.bne.es/.

73 Castro y Calvo, José María: Obras completas de..., p. XXXV.

74 El Católico, 30/8/1845. Diario constitucional de Palma, 8/9/1845, BNE, http://hemerotecadigital.bne.es/. 
lo que se puede considerar como una misión diplomática, de forma repentina en el verano de ese año a pesar de haber viajado su madre a Madrid para estar con él ${ }^{75}$.

Por otro lado, la crisis económica e industrial que se iba acentuando por entonces terminaría provocando movimientos revolucionarios en 1848, año en el que el 21 de febrero aparece publicado en Londres el Manifiesto de Marx y Engels. Los conflictos sociales se extendieron por Europa, especialmente en Francia y Alemania, generado en España intentos de sublevación contra el gobierno de Narváez alimentados por algunos liberales y progresistas, que fracasarían por mala planificación y la dura represión ejercida por el Gobierno.

Adrán Goás en la biografía de Nicomedes-Pastor Díaz señala que el escritor y político vivariense en la primavera de 1848 visitó Andalucía, donde presenciaría, además de algunas revueltas, las procesiones de Semana Santa en Sevilla y que luego visitó Málaga y Granada, sin dar más detalles de estos viajes ${ }^{76}$.

Los periódicos en aquellos momentos publicarían una serie de noticias que pueden aclarar esta cuestión. Por esas fechas, informarían de la insurrección general en Andalucía, señalando El Heraldo del 11 de abril de 1848 que habían sido detenidos en Sevilla Escosura y el general Ruiz, siendo conducidos al castillo de Santa Catalina en Cádiz, así como de la fuga de Olózaga en Córdoba. Asimismo, notificaría que estaba punto de llegar a Sevilla Nicomedes-Pastor Díaz para continuar el viaje inmediatamente a la Corte. Sin embargo, el escritor vivariense permanecería en Andalucía en aquellos momentos como se desprende de la información del periódico madrileño del 24 de mayo, en la que se señalaba que habían llegado a Cádiz Nicomedes-Pastor Díaz y el Diputado a Cortes García Barzanallana, encontrándose ya en aquella ciudad el Diputado Bermúdez de Castro ${ }^{77}$.

Por cartas dirigidas a su madre se aprecia que el escritor vivariense permaneció un largo espacio de tiempo en Sevilla, desplazándose posteriormente en mayo a Málaga y en junio a Granada. Seguramente, tratando de huir de la situación en Madrid, que era "bajo todos conceptos harto aflictiva y mala", y no dudando en escribir que "no tendría maldita la gracia que fuera yo ahora a comprometerme por cuenta del general Narváez". Estas cartas ponen de relieve las distintas posturas que adoptaron los políticos del Partido Moderado en aquellos momentos, ya que, mientras Donoso Cortés apoyaba abiertamente las medidas represoras de Narváez, otros como Pacheco y Nicomedes-Pastor Díaz estimaban que no podían presentarse ante el Parlamento mientras estuviesen separados los Augustos Esposos, conviniendo retirarse de la Corte si no se conseguía su reconciliación. Ahora bien, los numerosos desplazamientos que realizó Nicomedes-Pastor Díaz por diversas ciudades andaluzas en aquellos momentos hacen suponer unas gestiones que van más allá de la simple ausencia de Madrid, ya que, por ejemplo, tres días más tarde que Narváez suspendiese las Cortes el 22 de mayo, escribió que presenció la sublevación de un cuartel en Sevilla y que "los príncipes llevaron un susto tremendo", frase que puede justificar su presencia en la ciudad junto con los miembros de la familia real española ${ }^{78}$.

75 Enrique Chao Espina: Pastor Díaz dentro del Romanticismo..., p. 99 y 454.

76 Adrán Goás, Carlos: Nicomedes Pastor Díaz. Alicante: Biblioteca Virtual Miguel de Cervantes, 2012. Edición digital a partir de Santiago de Compostela, Xunta de Galicia; Dirección Xeral de Promoción Cultural; Consellería de Cultura, Comunicación Social e Turismo, 1998, 44.

77 El Heraldo, 11/4 y 24/5/ de 1848, BNE, http://hemerotecadigital.bne.es/.

78 Chao Espina, Enrique: Pastor Díaz dentro del Romanticismo..., pp. 116 a 118. 


\section{Consideraciones finales}

Nicomedes-Pastor Díaz ha pasado a la posteridad como un notable escritor y visible político español del siglo XIX, siendo considerado en la actualidad generalmente como liberal, aunque él mismo se definía como conservador ${ }^{79}$.

El Presidente del Consejo de Ministros, en la sesión de las Cortes que se aprobó conceder a la madre de Nicomedes-Pastor Díaz una pensión, resaltaría que la vida del político vivariense fue honrada y sin mancha, y que, habiendo llegado a una gran altura en los empleos públicos, había muerto pobre. Su buen amigo y admirador Juan Valera señalaría en este acto que fue un político consecuente y había servido al Estado con lealtad, siendo fiel a su Partido. Asimismo, destacaría que fue un poeta notable, un literato ameno, florido y lleno de efusión ${ }^{80}$.

Posteriormente, el escritor daría la siguiente imagen del ilustre vivariense que se puede considerar representativa de su paso por la política española: "El liberalismo de D. Nicomedes nunca dejó de estar en perfectísima consonancia con su religiosa ortodoxia y con su fe ardiente y firme en la católica doctrina. Acaso, al menos en mi sentir, dicha fe fue algo exagerada" $"$.

En relación con su etapa política, Chao Espina, cronista oficial de la villa natal del ilustre personaje vivariense, señalaría que los biógrafos de Nicomedes-Pastor Díaz abren un paréntesis de nueve años a partir de 1843, en el cual apenas señalan más hitos que su nombramiento como Secretario General del Banco de Isabel II ${ }^{82}$.

Los datos recogidos en el presente trabajo han permitido clarificar esta cuestión. Tras sus primeros pasos como Jefe Político, antecedente de los Gobernadores Civiles, destacaría por su actuación contra el gobierno de Espartero, junto con otros destacados personajes de la época. Este grupo, paralelamente a su actuación política, contaría con una significativa prensa afín para fundamentar sus posicionamientos. Es de resaltar que en aquellos momentos los periódicos se convertirían en un factor clave en la lucha contra Espartero, ejerciendo en ellos Nicomedes-Pastor Díaz un periodismo comprometido y combativo. Por otro lado, en esta faceta alcanzaría una notable notoriedad y, al margen de sus escritos, los periódicos difundirían sus posicionamientos hasta su fallecimiento, destacando sus discursos contra el socialismo o fragmentos de la obra que había escrito en defensa del Pontificado.

Al inicio de la Década Moderada, compaginaría su actividad política como Diputado con importantes cargos desempeñados en sociedades relacionadas con el lobby político-financiero que se formó tras la caída de Espartero y en el que tendría un papel destacado el Marqués de Salamanca, que generaría sustanciales beneficios económicos para este político y empresario, así como para la reina regente, María Cristina de Borbón y Dos Sicilias, y su marido el duque de Riansares.

A pesar de los escándalos financieros protagonizados, el Marqués de Salamanca tendría al inicio de 1847 un papel destacado en el Gobierno de la nación con Joaquín Pacheco, buen amigo de Nicomedes-Pastor Díaz y con el que colaboraría tanto en política como en la prensa. Es en esos momentos cuando el político vivariense con-

\footnotetext{
79 Diaz, Nicomedes-Pastor: A la Corte y a los partidos: palabras de un diputado conservador sobre las principales cuestiones de nuestra situación política. Madrid, Imp. de Corrales y Compañía, 1846.

80 El Contemporáneo, 12/4/1863, BNE, http://hemerotecadigital.bne.es/.

81 Valera, Juan: Crítica Literaria (1901-1905) ..., pp. 18 a 26.

82 Chao Espina, Enrique: Pastor Díaz dentro del Romanticismo ..., p. 97.
} 
seguiría su ascensión política, primero como subsecretario del recién creado Ministerio de la Gobernación y seguidamente como titular de la cartera del Ministerio de Comercio, Instrucción y Obras Públicas hasta el 31 de agosto de 1847.

En ese ministerio se autorizarían operaciones irregulares y polémicas, aunque las responsabilidades por los numerosos enriquecimientos indebidos a costa del Estado se difuminarían en aquellos momentos. A los nueve días de dejar el cargo de ministro señalado, Nicomedes-Pastor Díaz sería nombrado Rector de la Universidad Central de Madrid. Asimismo, en aquellos momentos tomaría posesión como académico de la Real Academia Española de la Lengua o mantendría una destacada presencia en otras Instituciones, como el Ateneo de Madrid, o figuraría matriculado en el Colegio de Abogados de la capital del Reino.

Al final de la Década Moderada, las actividades públicas de Nicomedes-Pastor Díaz se irían restringiendo tras su cese como Rector y de forma paralela a su alejamiento de los últimos gobiernos de esa etapa política. Con el Bienio Progresista y posteriores gobiernos, el escritor vivariense vuelve a tener un destacado papel en la política nacional hasta su fallecimiento, retornado igualmente a la vida pública española con importantes reconocimientos, como su ingreso en la Academia de Ciencias Morales y Políticas.

Por otro lado, Castro Calvo señalaba que resultaba llamativo que en sus biografías quedasen puntos sin esclarecer, especialmente los relativos a los viajes que realizó, o que los numerosos cargos que ostentó se considerasen generalmente como "gracia llovida del cielo" 83 .

Al margen de su incuestionable valía personal reconocida por todos sus biógrafos, a la vista de los datos analizados se aprecia que Nicomedes-Pastor Díaz desarrollaría con celo y fiel cumplimiento del deber los cometidos que le fueron encomendados en la política española, actuaciones que se deben ver en el contexto de esos años y dentro del compromiso político que mantuvo junto a un destacado grupo de personalidades de la época con el que estaría vinculado y que contarían con él a lo largo de su carrera política. Todo ello, dentro de sus firmes convicciones y de su manifiesta fidelidad al trono de Isabel II y a su madre María Cristina de Borbón Dos Sicilias durante su Regencia.

En consecuencia, se estima que su trabajo e implicación con una determinada corriente política desde el principio de sus actividades le permitirían ascender hasta alcanzar puestos de máxima responsabilidad en diferentes gobiernos a lo largo de toda su vida, a excepción de un pequeño paréntesis al final de la Década Moderada.

En relación con el objetivo de este estudio y a la vista de los datos recopilados, se aprecia que Nicomedes-Pastor Díaz tuvo un destacado papel en el lobby políticofinanciero que se formó al inicio de la Década Moderada, actividad que no ha sido suficientemente desarrollada en sus biografías, a pesar de la pública y notoria difusión por la prensa de entonces, así como su matriculación en el Colegio de Abogados de Madrid coincidiendo con su etapa empresarial.

En esos años, surgirían grupos de poder económicos vinculados con la Corona y con clase política del momento. Sin embargo, no se ha podido apreciar en los últimos años de la Década Moderada, ni posteriormente, actuaciones relacionadas con el ámbito empresarial en las que interviniese Nicomedes-Pastor Díaz. En consecuencia, se

83 Castro y Calvo, José María: Obras completas de Don Nicomedes..., p. XLII. 
puede deducir que se desmarcó de un tipo de actividades poco edificantes que siguieron manteniendo algunas personas con las que había colaborado con anterioridad, especialmente con el Marqués de Salamanca.

Por último, cabe significar que, como se ha podido ver, en la Década Moderada se produjeron, usando la terminología coloquial actual, un pelotazo bursátil en la Bolsa de Madrid, la crisis bancaria del Banco de Isabel II, financiaciones ilegales y la utilización de empresas, especialmente las de ferrocarriles, para conseguir desmesurados enriquecimientos personales. Todo ello, en una situación económica cada vez más complicada en el país, que terminaría en la siguiente década generando la primera crisis financiera de la historia del capitalismo español y que afectaría igualmente a otros sectores, especialmente al inmobiliario, donde la especulación del suelo produciría lo que se conoce actualmente como una burbuja inmobiliaria y acarrearía el desplome del mercado. Estos hechos, que tuvieron lugar cerca de hace dos siglos, se estima que son similares a los acaecidos recientemente en nuestro país.

\section{Archivos y Bibliotecas}

Biblioteca de la Comunidad de Madrid, www.bibliotecavirtualmadrid.org/

Biblioteca municipal de Viveiro, http://viveiro.es/

Biblioteca Nacional de España, http://hemerotecadigital.bne.es/

Biblioteca Virtual de Prensa Histórica, http://prensahistorica.mcu.es/

Biblioteca Virtual Miguel de Cervantes, www.cervantesvirtual.com/

BOE, gacetas históricas, www.boe.es/

Colegio de Abogados de Madrid, Secretaría, Biblioteca y Servicio de Documentación Jurídica, http://web.icam.es/

Congreso de los Diputados, www.congreso.es/

Galiciana, Biblioteca de Galicia, http:/galiciana.bibliotecadegalicia.xunta.es/

Hemeroteca Municipal de Madrid, www.madrid.es/

\section{Hemeroteca}

Boletín de Noticias de A Coruña, 1843

Boletín de Segovia, 1838

Diario constitucional de Palma, 1845

Diario oficial de avisos de Madrid, 1846-1847

Eco del Comercio, 1839-1847

El Católico, 1844-1845

El Centinela de Galicia, 1843

El Clamor Público, 1844-1848

El Conservador, 1841

El Contemporáneo, 1863

El Correo Nacional, 1840

El Español, 1845-1848

El Guardia Nacional, 1839

El Heraldo, 1843-1848

El Imparcial, 1846-1870 
El Popular, 1847

El Sol, 1843

Gaceta de Madrid, 1847-1863

La Abeja, 1835

La América, 1863

La Concordia, 1863-1864

La Discusión, 1857-1873

La Época, 1850-1853

La España, 1853

La Esperanza, 1846-1847

La Ilustración, 1854

La Ilustración española y americana, 1883

La Nación, 1854

La Patria, 1849-1851

La Posdata, 1843

\section{Referencias bibliográficas}

Adrán Goás, Carlos: Nicomedes Pastor Díaz. Alicante: Biblioteca Virtual Miguel de Cervantes, 2012. Edición digital a partir de Santiago de Compostela, Xunta de Galicia; Dirección Xeral de Promoción Cultural; Consellería de Cultura, Comunicación Social e Turismo, 1998.

Artola, Miguel: Partidos y Programas Políticos, 1808-1936: manifiestos y programas políticos. Alianza Editorial, Madrid, 1991.

- La burguesía revolucionaria (1808-1874). Alianza Editorial, Madrid, 2006.

Bahamonde, Ángel y Martínez, Jesús Antonio: Historia de España, Siglo XIX. Editorial Cátedra, 2007.

Banco de Isabel II: Estatutos y reglamento del Banco de Isabel II. 1844.

Banco Español de San Fernando: Representación elevada a S.M. por la Junta de Gobierno del Banco Español de San Fernando: pidiendo que se la ampare en la posesión de la facultad privativa de emitir billetes pagaderos a la vista al portador, de la que se le ha despojado por la erección del nuevo Banco de Isabel II con la misma y más amplia facultad, y demostrando la ilegalidad de semejante concesión y los gravísimos inconvenientes económicos que de ella resultan. 1846.

Blaney, Gerald: "La historiografía sobre la Guardia Civil. Crítica y propuestas de investigación". Politica y Sociedad, 2005, 3, pp. 31-44.

Burdiel, Isabel: Isabel II o el laberinto del poder. Madrid: Taurus, 2016.

Cánovas Sánchez, Francisco. El Partido Moderado. Madrid: Centro de Estudios Constitucionales, 1982.

Castro y Calvo, José María: Obras completas de Don Nicomedes-Pastor Díaz. Biblioteca de autores españoles, Atlas Ediciones, Madrid, 1969.

Chao Espina, Enrique: Pastor Díaz dentro del Romanticismo. Alicante: Biblioteca Virtual Miguel de Cervantes, 2012. Edición digital del Instituto de Estudios Viveireses, Viveiro, 1995.

Díaz, Nicomedes-Pastor: La cuestión electoral en diciembre de 1839 y enero de 1840. Cáceres, Imprenta de don Lucas Burgos, diciembre de 1839. 
- A la Corte y a los partidos: palabras de un diputado conservador sobre las principales cuestiones de nuestra situación política. Madrid, Imp. de Corrales y Compañía, 1846.

- Obras de Don Nicomedes-Pastor Díaz, de la Real Academia Española. Tomo II. Alicante: Biblioteca Virtual Miguel de Cervantes, 1999. Publicación original: Madrid, Imprenta de Manuel Tello, 1866.

- Italia y Roma. Roma sin el Papa. Madrid, Imp. de Manuel Tello, 1866.

- Los problemas del socialismo: lecciones pronunciadas en el Ateneo de Madrid en el curso de 1848 a 1849 / por Nicomedes-Pastor Díaz. Madrid, Imp. de Manuel Tello, 1867.

- Biografía de Don Diego de León, primer conde de Belascoain. Madrid, Imp. de Manuel Tello, 1868.

- Diez años de controversia parlamentaria. Discursos parlamentarios. Madrid, Imp. de Manuel Tello, 1868.

- Memorias de una campaña periodística. Madrid, Imp. de Manuel Tello, 1868.

- Obras políticas. Fundación Caja de Madrid. Barcelona: Anthropos, 1996.

Donapetry Iribarnegaray, Juan:. Historia de Vivero y su Concejo. Viveiro, Imp. A. Santiago, 1953.

Fernández Torres, Luis: "Nicomedes Pastor Díaz y la idea de los partidos políticos en el moderantismo español (1836-1846)". Vínculos de Historia, 4, 2015, pp. 295-317.

Fernández-Sanguino Fernández, Julio: Viveiro en la prensa histórica (1741-1850). Madrid, Visión Libros, 2012.

— "Nicomedes-Pastor Díaz en el entramado político-financiero de mediados del siglo XIX y su correlación con la política actual". Xornal de Galicia, 01/12/2015, Edición Digital, Sección Opinión.

- "Nicomedes-Pastor Díaz Corbelle en el Colegio de Abogados de Madrid (1845-1853). Heraldo de Vivero, 20/05/2016, p. 4.

Fontana, Josep: La época del liberalismo. Vol. 6 de la Historia de España, dirigida por Josep Fontana y Ramón Villares. Barcelona: Crítica/Marcial Pons, 2007.

Fuentes, Juan Francisco: El fin del Antiguo Régimen (1808-1868). Politica y sociedad. Madrid: Síntesis, 2007.

Hernández Sandoica, Elena y Peset Reig, José Luis: Universidad, poder académico y cambio social: (Alcalá de Henares 1508-Madrid 1874). Madrid, Ministerio de Educación, 1990.

Ovillo y Otero, Manuel (dir.): Historia de las Cortes de España y Biografias de todos los Diputados y Senadores más notables contemporáneos. Tomo II, Imp. Baltasar González, Madrid, 1847.

Piqueras, José Antonio: La esclavitud en las Españas: Un lazo transatlántico. Madrid, Catarata, 2012.

Puente y Apecechea, Fermín de la: "Noticia biográfica". Obras de D. Nicomedes Pastor Díaz. Tomo I, Madrid, 1866.

Rivero, Manuel y Pro, Juan: Breve atlas de historia de España. Madrid, Alianza Editorial, 2006.

Sánchez Albornoz, N.: "La crisis de 1866 en Madrid: la Caja de Depósitos, las sociedades de crédito y la Bolsa". Moneda y Crédito, 100, 1967, pp. 3-40.

Sánchez García, Raquel: "El Marqués de Salamanca y la amortización de los ferrocarriles". Cuadernos de Historia Contemporánea, 25 (2003), pp. 199-215.

Santillán, Ramón de: Memoria histórica sobre los bancos Nacional de San Carlos, Español de San Fernando, Isabel II, Nuevo de San Fernando, y de España. Madrid, T. Fortanet, 1865. 
Sardá Dexeus, Juan: La política monetaria y las fluctuaciones de la economía española en el siglo XIX. Ariel. 1970.

Seoane, María Cruz y Saiz, María Dolores: Cuatro Siglos de Periodismo en España. De los avisos a los periódicos digitales. Madrid, Alianza Editorial, 2007.

Tedde de Lorca, P.: El Banco de San Fernando (1829-1856). Banco de España. Madrid, Alianza Editorial, 1999.

Tortella, Gabriel: El desarrollo de la España contemporánea. Historia económica de los siglos XIX y XX, Madrid, Alianza Universidad, 1994.

Tortella, Gabriel (dir.): La Banca española en la Restauración. Rafael Anes Álvarez y otros, edición y revisión a cargo de Pedro Schwartz. Madrid, Banco de España, 1974.

Valera, Juan: Obras completas, tomo II, Madrid, Aguilar 1961.

— "Notas biográficas y críticas: Nicomedes Pastor Díaz". Crítica Literaria (1901-1905): La poesía lírica y épica en la España del siglo XIX. Madrid, Imprenta Alemana, 1912, pp. 18 a 26.

- Revista La América, "Necrología de Nicomedes-Pastor Díaz", 12 de abril de 1863.

Vera Santos, José Manuel: La reforma constitucional en España. Las Rozas, Madrid, La Ley, 2007.

Zavala, José María: "María Cristina de Borbón, en la picota”. La Aventura de la Historia, 91. Madrid, Arlanza ediciones S.A., 2006, p. 44-49.

Zumalacárregui, Leopoldo: El Banco de Isabel II y la crisis de la Banca de emisión española de 1847. Madrid, Gráficas Reunidas, 1952. 